\title{
A Confluence of Tech and Talent: Rural Online Entrepreneurship and Return Migration
}

\author{
Wesley Koo \\ INSEAD, Strategy Department \\ wesley.koo@insead.edu
}

\author{
Charles Eesley \\ Stanford University, Management Science \& \\ Engineering Department \\ cee@stanford.edu
}

\begin{abstract}
We show that return mobility (the ability for migrants to return to their home regions) and the lifting of return barriers is a crucial enabling factor for the performance and growth of rural e-commerce businesses. We use a natural experiment involving a regional policy change, which reduced the barriers for rural migrants to return in one Chinese province but not in others. We find that after the policy change, rural e-commerce businesses in the province that implemented the policy change enjoyed a performance gain relative to those in other provinces. We also find higher rates of business founding and relocation to rural areas in that province post-policy change. Meanwhile, male-led rural e-commerce businesses enjoyed disproportionately larger performance gains than female-led businesses in that province. This study highlights the importance of return mobility and return barriers in structuring entrepreneurial activities.
\end{abstract}

\section{Introduction}

Over $40 \%$ of the world's population and $85 \%$ of the world's acutely poor reside in rural areas, where there is a dearth of entrepreneurial opportunities [1]. One potential enabler of rural entrepreneurship is return migration. Rural migrants who return to their home villages typically have worked urban jobs and possess higher levels of education, business experience, technical skills, and entrepreneurial tendency than rural residents who have never migrated [2]. Research on international migration also suggests that return migrants from advanced economies, after moving back to their home regions, helped create more entrepreneurial ventures and more innovation $[3,4]$.

However, rural areas rarely attract entrepreneurial migrants to return, as geographic isolation makes it difficult for rural businesses to access the urban market [5]. Some have suggested that digitization, which allows rural businesses to access the wider market remotely, may allow talented migrants to return home and work away from urban centers [6]. However, we have yet to see much evidence of online entrepreneurship making inroads in rural areas [7]. Despite the potential of digital technologies to connect remote regions to the wider market and make distance less relevant, cities still offer a host of advantages over rural areas, including pooled resources and offline information channels [8]. Such rural disadvantages would likely dissuade rural migrants from returning and operating businesses from home.

In this study, we investigate how return migration affects the patterns and performance of rural online entrepreneurship. Two related streams of research on mobility serve as guideposts for initial theorization. First, the literature on mobility and knowledge transfer conceptualizes individuals as conduits of knowledge [4]. Through knowledge spillovers, individuals transfer valuable information and best practices to other individuals located their destination regions [9]. Knowledge is localized because collocated individuals exchange knowledge more easily, and national and regional borders demarcate different knowledge pools [10]. Due to these reasons, much of the literature finds that the mobility of individuals is associated with higher rates of entrepreneurship in the destination regions to which those individuals relocate [9].

A related set of research studies the effects of mobility barriers on economic and entrepreneurial outcomes. Current research in particular has focused on the role of noncompete agreements in the U.S. context. This research shows that noncompetes deter and redirect the mobility of high-skill workers including inventors and top managers, creating costs in acquiring new jobs and starting new businesses especially within jurisdictions where noncompetes are enforced [11]. Thus, noncompetes make it difficult for potential entrepreneurs to force a release from their current employers, thereby increasing the cost of recruiting from the labor market. The enforcement of noncompetes in Michigan resulted in a "brain drain" of inventors to other states where noncompetes were proscribed, and the brain drain effect was especially pronounced among more collaborative and more impactful inventors [11]. Broadly, the mobility research shows that increased worker mobility is associated with more entrepreneurship in workers' destination firms or destination regions. There are two 
gaps in knowledge. First, we know little about talent mobility in the context of digital business and online entrepreneurship. Digital tools, usually provided by digital platforms, may open up new entrepreneurial opportunities in remote or underdeveloped areas, but relatively little evidence exists to show whether mobile individuals are indeed leveraging those tools to pursue entrepreneurship. Second, there has yet to be much research on return mobility and return barriers.

We study a particular migration policy change that reduced the barriers to return migration in a specific region at a specific point in time. Leveraging this natural experiment, we causally estimate the impact of increased return mobility (reduced return barriers) on the patterns and performance of rural online entrepreneurship. We find that rural ecommerce businesses (REBs) in one Chinese province that implemented the migration policy change (Jiangsu) saw 19\% sales increase after the policy change relative to REBs in surrounding provinces that did not experience the same policy change during that time period. Jiangsu, after the policy change, also saw a higher rate of REB founding and a higher rate of urban e-commerce businesses relocating to rural areas relative to other provinces. Additionally, gender analysis reveals that male-led REBs in Jiangsu benefited disproportionately more than female-led REBs. Using a mechanism test, we show that the gender disparity is likely driven by the possibility that return migrants are mostly male and that male-led REBs are better able to absorb and utilize male return talent. To further strengthen the validity of our main results, we carry out a host of additional analyses: a focused analysis of performance effects at the JiangsuShandong border regions where local economies and cultures are highly similar, a synthetic control analysis, a between-effects analysis to highlight the generalizability of our results, and a placebo tests using data on urban businesses.

This study provides two research contributions. First, it attempts to bridge the research on digitization with the mobility literature. As an increasing amount of entrepreneurship and business activities take place in the digital sphere, it is important to study whether and when the mobility of individuals affects the business landscape, especially in regions that are traditionally characterized as unfavorable destinations for mobile individuals. Existing research suggests that talent agglomeration remains important for knowledge transfer and entrepreneurship even in the presence of digital tools $[11,12)$. This study shows that talent deagglomeration is indeed enabled by digitization, but it needs to be accompanied by flexible policy. Second, this study highlights the role of return mobility and return barriers in structuring economic and entrepreneurial outcomes in migrants' home regions. Return mobility is understudied even though return migrants are an important driver of business and entrepreneurship [3]. Compared to the case of regular mobility barriers (e.g., immigration systems in developed countries), it is unclear whether the lifting of return barriers would lead to positive economic or entrepreneurial outcomes. This is because migrants' home regions are often marked by a dearth of entrepreneurial opportunities, market access, and complementary assets - reasons why migrants migrated outward in the first place. These existing deficiencies may lower migrants' desire to found new businesses in their home regions and, when they do, limit the performance and scalability of their businesses. Our study is among the first to highlight the presence of return barriers as a salient hindrance to local entrepreneurship.

Additionally, this study provides practical lessons for digital platforms and for policymaking. Despite the potential of digital technologies to connect remote entrepreneurs with the wider market, talent is oftentimes the missing piece. By studying whether and when return migrants leads to higher-quality entrepreneurship in rural areas, our study informs the types of complementors platforms should focus on onboarding, especially regarding the development of platform business in remote and underdeveloped regions. This study also informs policymaking by showing how a confluence of technology and talent may enhance the rural entrepreneurial ecosystem and potentially aid economic development in rural areas. Meanwhile, the finding that female-led businesses underperform in the midst of increased return migration calls for more research and attention toward how different segments of entrepreneurs are affected by return migration.

In Section 2, we detail the empirical setting, data, variable construction, and strategy for causal inference. In Section 3, we present the main results on the impact of return mobility on the performance and patterns of rural online entrepreneurship. In Section 4, we supplement the main results with additional analyses and mechanism tests. In Section 5, we conclude with a set of research, managerial, and policy implications.

\section{Setting and Data}

\subsection{Migration Policy Change}

In this study, we exploit a migration policy change that was implemented in China's Jiangsu province in November 2013. To understand the policy 
change, one needs to first understand China's longstanding hukou residency system. The hukou is a population control system that has become one of China's hallmark policies in the past sixty years. Most notably, it divides the population into residents carrying rural versus urban residency statuses and restricts the use of urban resources such as education, pension, healthcare, and housing to those with urban status only [13]. As a result, the urban status often appears highly desirable to many rural migrants working in cities. Although different provinces have different requirements for hukou acquisition, rural migrants typically need to show continuous urban employment and enrollment in the urban healthcare system for three to five years in order to receive the urban status [14]. Due to this requirement, low-skilled rural migrants, who tend to conduct manual labor and seek short-term labor contracts, would return home during down seasons, but high-skilled rural migrants tend to pursue the urban status and stay in cities [14]. Under the traditional residency system, migrants seeking urban status, who tend to be high-skilled and more talented, were required to spend most of their time in cities and could rarely return to their home villages. This barrier prevented them from fully engaging in the rural economy [15].

In November 2013, a new residency policy was implemented in Jiangsu province. It introduced a new urban residency permit for rural migrants. Under the new system, a migrant can easily obtain an urban residency permit while still waiting in line for their official urban status [16]. Continuous urban employment and enrolment in urban health insurance would no longer be a prerequisite for obtaining the urban status, and the new permit can be phased into the urban status over time. An analogy to the western context is if the U.S. immigration system dropped the requirement that Green Card holders must stay in the U.S. for the majority of a year in a five-year period to be naturalized as citizens. Thus, the Jiangsu policy change gives many urban status-seeking migrants significant leeway to move back to their home villages because they may now carry their new residency permits and avoid losing their place in line for the urban status.

\subsection{Data and Variables}

2.2.1. Data Source. The data for this study were gathered from two sources. First, we acquired internal access to business-level panel data from a leading ecommerce platform in China whose gross merchandise volume is on the order of 100 billion USD. On this "C2C" e-commerce platform, all businesses are operated by individual entrepreneurs as opposed to by the platform. The panel data for this study consists of 2,212 randomly selected e-commerce businesses located in the rural parts of eastern China. The window of observation is from May 2013 to April 2014, the twelve-month window around the policy change in November 2013 (six months before and six months after). The data is at the business-monthly level. 1,594 of the REBs had listed products for sale for at least one month during the twelve-month window. Finally, time-invariant data was collected from national-, province-, prefecture-, and countylevel yearbooks and from local policy bureaus. This data is primarily used to construct the matching analysis and to conduct subsample analysis.

2.2.2. Dependent Variables. The first dependent variable is a business's monthly Sales performance. One feature of the dataset is that all monthly data on sales is normalized, meaning that the sales numbers are divided by one unknown number to ensure each entrepreneur's anonymity. The average Sales in the dataset is 25.0 per month for businesses that sold products. A back-of-the-envelope calculation shows that each unit of sales corresponds roughly to 60 USD, which means the average business makes about 1500 USD in revenue per month. However, given the uncertain nature of this approximation, we take the logarithm of all sales numbers, $\log$ (Sales), and interpret effect sizes in percentage terms.

The second dependent variable is a business's Innovation performance. Common practice in the literature is to measure business's innovation as its patent count. However, this practice does not extend well into entrepreneurship in the context of digital platforms, where businesses rarely patent. Instead, we measure innovation as the number of distinct products a business lists per month. The assumption is that an increase in the count of distinct product items signifies the enriching of one's product line, which is an important form of innovation for online entrepreneurs. We take the logarithm of the number of products to interpret the effects in percentage terms. The third dependent variable is number of businesses founded (Num. Founded). Since it is difficult to study founding at the individual business level (all businesses in our sample have been founded at some point in time), we operationalize founding at the prefecture-month level and count the number of businesses founded in a given prefecture in a given month.

2.2.3. Independent and Control Variables. The independent variable is the interaction term between the policy change variable Post-PC and the binary variable Jiangsu, which indicates whether a REB is located in Jiangsu province. Since the policy change 
became effective in November 2013, we treat the months up until November as pre-change (Post-PC $=$ $0)$. The months starting in November 2013 will be considered post-change $($ Post- $P C=1)$. The interaction term thus becomes Post-PC X Jiangsu.

Additionally, we control for a vector of businessspecific variables that might influence entrepreneurial outcomes. First, we control for the average price in a business's product line, which is measured by taking the average of the prices of all products in a given month. Per data agreement, we only had information on the products in a business's top three-grossing categories. Price data are normalized by an unknown number, and we take the logarithm of Price, $\log$ (Price) in our analysis. Second, we control for the monthly average Buyer Rating (maximum score $=5$ ) assigned by buyers to an online business in a given month. Finally, we include Month Dummies to control for unobservable factors that are seasonal or temporal in nature.

\subsection{Methodology}

2.3.1. Difference-in-Differences Design. The main relationship of interest is how Jiangsu REBs will perform relative to non-Jiangsu REBs after the policy change, which would allow rural migrants who were seeking urban status in Jiangsu cities to more easily return to their home villages/townships. To test this relationship, we carried out a straightforward difference-in-differences framework at the businessmonth level, with sales as the dependent variables:

$$
\begin{gathered}
\log (\text { Sales })_{i t}=\beta_{0}+\beta_{1} \text { Jiangsu }+ \\
\beta_{2} \text { PostPC }_{t}+\beta_{3} \text { PostPC }_{t} \times \text { Jiangsu }_{i} \\
+\lambda C_{i t}+\tau \text { Month Dummy } \\
\alpha_{i}+u_{i t}
\end{gathered}
$$

In this specification, $C_{i t}$ represents the timevariant controls, and month dummies control for the time-specific effects. PostPC $C_{t} \times$ Jiangsu $_{i}$ is the treatment variable, which equals 1 if a business located is in Jiangsu province when the province has already passed the new migration policy. Our main hypothesis predicts that the coefficient on the interaction term should be positive and significant. Finally, $\alpha_{i}$ is the business-level fixed effects, and $u_{i t}$ is the idiosyncratic error term. In this study, all regressions are estimated using business fixed effects. The standard errors are clustered at the province-level.

The analysis for founding is conducted at the prefecture-month level. This is because every business in the sample had been founded before or during the window of observation, making business-level founding analysis difficult. Specifically, we estimate the changes in the rate of business founding after the policy change across different prefectures, using a similar difference-in-differences design as in the performance equation. The specification for founding analysis is presented below in Equation 2. The dependent variable is the number of new businesses founded in prefecture $p$, in month $t$. The last two terms are the prefecture-level fixed effects and the error term.

$$
\begin{gathered}
\begin{array}{r}
\text { Num.Founded } \\
\beta_{2} \text { PostPC }_{t}+\beta_{0}+\beta_{1}{\text { Post } P C_{t}} \times \text { Jiangsu }_{i} \\
+\lambda C_{p t}+\tau \text { Month Dummy }
\end{array}+ \\
\alpha_{p}+u_{p t}
\end{gathered}
$$

The identification strategy abides by the following logic. To measure the impact of the new migration policy on the performance of REBs, we would subtract the performance of REBs after the policy roll-out from the performance of REBs before the roll-out. However, other events and contemporaneous factors, such as macroeconomic trends, could also influence the patterns of REB performance. To ascertain that these factors do not affect the interpretation of our results, we simultaneously observe a control group of REBs whose performance change would likely be exposed to the aforementioned contemporaneous factors but not to the migration policy shock. By computing the "difference in differences" between the two groups of REBs, we thus obtain a causal estimate of the effects of the policy change on REBs.

2.3.2. Validity of the Identification Strategy. The identification strategy needs to satisfy these conditions to be valid: 1) the treatment event (migration policy change) needs to bring about relevant shifts in migration patterns, and 2) the treatment needs to be exogenous with respect to the outcome variables related to entrepreneurship. To support the first condition, we need to show that the migration policy change resulted in more rural migrants, especially highly skilled migrants, returning to the villages. The pattern of returning talent is supported by the population data.

In order for our identification strategy to satisfy the exclusion restriction, the policy change needs to be exogenous with respect to the performance of REBs and e-commerce performance in rural areas. Here, we address two specific concerns regarding the exclusion restriction. First, both the migration policy change and REB performance might have been driven by local economic trends in Jiangsu. For instance, Jiangsu's overall economy could have experienced high growth 
prior to the policy change, and the government could have aimed to reduce mobility barriers in order to continue the economic growth. In that scenario, Jiangsu REBs' performance could have increased relative to that of REBs in other provinces due to the continuous flourishing of the rural economy instead of due to the policy change. Another possibility is that rural economy could have been in a slump in Jiangsu prior to the policy change, and the government might have decided to boost the rural economy with the new policy. In that scenario, Jiangsu REBs' performance could have seen a relative increase due to regression to the mean instead of due to the policy change. To empirically address this concern, we first note that there was little fluctuation in rural economic growth or entrepreneurship in Jiangsu before the migration policy change, especially in comparison to the economic trends in nearby provinces. Additionally, we include control variables corresponding to local economic conditions, and we conduct a matching analysis that pairs Jiangsu REBs with REBs in other provinces that faced very similar local conditions.

\section{Results}

\subsection{Business Performance}

Table 1 is the summary statistics and correlation matrix. Our main analysis relates to the performance (sales and survival) of REBs. When plotting the sales of Jiangsu versus non-Jiangsu REBs over time, the lines prior to the policy change suggest a lack of preexisting trends in terms of sales differences. After the policy change, the Jiangsu line is consistently situated above the non-Jiangsu line, indicating a relative increase in sales among Jiangsu REBs. Five months after the policy change, the average Jiangsu REB outperformed the average non-Jiangsu REB by about $110 \%$ (in terms of dollar amount, roughly 2000 USD in monthly sales for Jiangsu REBs and 900 USD for non-Jiangsu REBs). Figure 1 maps the absolute change in average sales after the new policy for each province in our sample, showing that Jiangsu REBs experienced a particularly high sales increase.

The regression results are reflected in Figure 2, which plots the Kaplan-Meier survivor curve for the relocation patterns of Jiangsu versus non-Jiangsu urban e-commerce businesses (UEBs). After the policy change, there is a visibly widening gap between the survivor rate of Jiangsu UEBs and that of nonJiangsu UEBs. In terms of overall statistics, whereas $97 \%$ of the non-Jiangsu UEBs remained in urban areas by the end of the window (3\% moved to rural areas), only $95 \%$ of the Jiangsu UEBs remained urban businesses ( $5 \%$ moved to rural areas).

Additionally, we utilize coarsened exact matching (CEM) to create treatment REBs (Jiangsu) and control REBs (non-Jiangsu) that are highly similar along several variables in May 2013 (first month of the preperiod in our analysis): entrepreneur's gender, entrepreneur's age, business age, average price, and customer review score. Coarsening these matching variables into strata, the matching yields 454 REBs (306 non-Jiangsu, 148 Jiangsu). Importantly, the method has decreased the overall imbalance between treatment and control groups by $20.2 \%$ (the L1 measure decreased from 0.751 to 0.599 ). After that, we "feed" the matched sample of 454 REBs into the original difference-in-differences specification. The DiD results (available from the authors) show that Jiangsu REBs outperformed non-Jiangsu REBs by about $24 \%$ after the policy change $(\exp (0.219)-1=$ 0.24 ; p-value $=0.01$ ).

\subsection{New Business Founding and Performance}

We also examine the rate of founding of REBs in Jiangsu versus that in other provinces, before and after the policy change in November 2013. The founding of new businesses constitutes a measure of the extensive margin of the policy effects on total sales across regions. We only observe founded REBs in our sample, which makes it difficult to conduct the founding analysis at the business-level because there lacks a counterfactual group of potential entrepreneurs who do not end up founding businesses. Therefore, we aggregate the data to the prefecture-level and study the number of founding across prefectures over time. The unit of analysis is the prefecture-month, and there are 75 prefectures in the sample. Results available from the authors. Whereas the number of foundings increased across the board after the policy change, prefectures in Jiangsu saw 0.54 more rural ecommerce businesses being founded per month than prefectures in other provinces $(\mathrm{p}$-value $=0.01)$. Note that this result should not be interpreted in absolute terms because our sample is a randomly selected subsample of the total population of e-commerce businesses. In light of the average number of foundings in our sample prior to the policy change (1.93 foundings per prefecture per month), this increase translates into a $28 \%$ increase in REB founding at the prefecture-level in Jiangsu relative to in other provinces.

Next, we compare the relative sales advantage of existing REBs in Jiangsu over other REBs with that of the newly founded REBs in Jiangsu. This analysis 
constitutes a measure of the intensive margin of the policy effects, as it evaluates whether it is the existing Jiangsu REBs or the newly founded Jiangsu REBs that are outperforming non-Jiangsu REBs. In our sample, $63 \%$ of the REBs were founded prior to the policy change and $37 \%$ afterwards. To do this analysis, we include all the business-month observations in the sixmonth post-period and regress REB sales over the interaction term Jiangsu $X$ Founded After Policy Change and control variables in a set of pooled regressions. Regression results show that both existing REBs and newly founded REBs in Jiangsu have higher sales than their non-Jiangsu counterparts, but the coefficient on the Jiangsu X Founded After Policy Change interaction term is insignificant. In other words, the Jiangsu performance advantage observed in the main results can be attributed to both existing and new businesses doing better.

\section{Discussion and Conclusion}

This study contains three main findings. First, the lifting of return barriers via a migration policy change altered the performance patterns of rural e-commerce businesses (REBs). Relative to non-Jiangsu REBs, REBs in Jiangsu (province that implemented the policy change) enjoyed a $19 \%$ performance gain after the policy change. Jiangsu REBs also created more innovative product portfolios than non-Jiangsu REBs. These results are supported by a battery of robustness checks including a CEM analysis, a border-region analysis, and a synthetic control analysis. Second, we observe a higher rural founding rate and higher rate of urban business relocation in Jiangsu relative to in other provinces. Third, we find substantial gender imbalance in our results: male-led REBs in Jiangsu enjoyed a disproportionately bigger performance advantage after the policy change than female-led Jiangsu REBs did.

Our study contributes to the research on digitization and mobility. Despite the potential for digital tools to bridge gaps and bring about the "death of distance", most businesses still prefer urban areas and hub regions over rural and non-hub regions. Urban areas offer more complementary products and services than rural areas, and this advantage allows urban businesses to conduct more complex activities digitally [12]. As digital technologies improve, those technologies increase the returns to innovative ideas and allow idea-producing cities such as New York and San Francisco to benefit disproportionately more than other cities [19]. With the rise of digital technologies, national and state borders seem to exert an even stronger constraining effect on knowledge diffusion
[10]. Whereas prior research highlights the heightened importance of talent agglomeration and knowledge concentration in the era of digitization, our study provides some of the first empirical evidence that returning talent to rural areas may lead to successful online entrepreneurship. In the process, our study builds upon prior research by identifying a potentially critical condition for generating positive economic and entrepreneurial outcomes through digitization in remote and traditionally underdeveloped regions - the return of human talent.

This study also enriches current understanding of mobility and entrepreneurship by foregrounding the concept of return barriers and return mobility. Most studies on mobility barriers focus on barriers that prevent individuals from moving from less developed regions to more developed regions. This study shows that return mobility is not a given: significant return barriers may impede migrants from moving back to their less developed home regions. Meanwhile, there exists a stream of literature on the economic and entrepreneurial impact of returnees in the international context. These studies have generally found that returnees, typically returning from more advanced economies to their home countries, cast a positive influence on the performance of local firms due to their possession of non-local knowledge and their ability to acquire resources more efficiently [3], especially when returnees are embedded in local networks [17]. More recently, Luo and colleagues conceptualize Chinese returnees from abroad as "institutional carriers," who are uniquely able to transfer foreign ideas (e.g., corporate social responsibility practices) to local businesses [18]. Whereas these returnee studies generally treat the level of return migration as a given, our study shows that migrants' decisions to return are non-trivial because migrants are hindered by pre-existing barriers, the lifting of which may generate new and betterperforming businesses. Moreover, our study also differs from prior work by focusing on return migration in the domestic, rather than international, context. In doing so, we show that within-country talent flow is an important source of entrepreneurial competence, especially for traditionally underdeveloped and non-hub regions.

Our finding on gender differences contributes to the ongoing conversations on gender and entrepreneurship [20]. By showing that female-led REBs benefited less than male-led REBs from return migration, our study points to a potentially novel contributing factor to gender disparity in entrepreneurship: the ability of entrepreneurs to absorb and utilize mobile talent. Our mechanism test 
suggests that one potential mechanism underlying the gender disparity is that most return migrants are male and male entrepreneurs are better able to communicate with and benefit from male returnees due to gender homophily. There is an important implication associated with this result: if most rural-to-urban migrants are male, their return to their home regions could worsen regional gender gaps in entrepreneurship. Meanwhile, there are likely other mechanisms driving the gender disparity, and future research may further explore the gendered dynamics between existing entrepreneurs and returning talent.

Finally, this study provides an important set of policy implications. In their 2012 paper, Forman, Goldfarb, and Greenstein find that the spread of Internet adoption exacerbated economic inequality across regions [12]. They argue that a common pitfall of digitization policies is that those policies focus on physical and capital investments while largely neglecting the human capital aspect. This study provides direct evidence supporting the need for human capital to complement digitization effort. Specifically, it highlights the role of policymakers in enabling talent flows to accompany the dissemination of digital technologies. Interestingly, the policymakers behind the migration policy change in our study likely did not have digitization in their mind when designing the policy, suggesting that government policies need not be "digital policies" in order to spurt positive changes through the adoption of digital tools. Rather, governments and digital platforms may work together to create a confluence of technology and talent.

\section{References}

[1] S. Alkire, Santos ME. 2014. "Measuring Acute Poverty in the Developing World: Robustness and Scope of the Multidimensional Poverty Index", World Development 59: 251-274.

[2] C.Y. Liu, Ye L, Feng B. 2019. "Migrant entrepreneurship in China: entrepreneurial transition and firm performance", Small Business Economics. Springer New York LLC 52(3): 681-696.

[3] P. Choudhury. 2016. "Return migration and geography of innovation in MNEs: A natural experiment of knowledge production by local workers reporting to return migrants. Journal of Economic Geography 16(3): 585-610.

[4] Saxenian A. 1994. "Regional Advantage: Culture and Competition in Silicon Valley and Route 128", Harvard University Press: Cambridge, MA.

[5] Y. Zhao. 2002. "Causes and Consequences of Return Migration: Recent Evidence from China." J. Comp. Econ. 30(2):376-394.

[6] S. Cecchini, Scott C. 2003. "Can information and communications technology applications contribute to poverty reduction? Lessons from rural India", Information Technology for Development 10(2): 7384.

[7] Greenstein S, Prince J. 2007. "Internet diffusion and the geography of the digital divide in the United States." In The Oxford Handbook of Information and Communication Technologies, Mansell R, Avgerou C, Silverstone R, Quah D (eds). Oxford University Press: Oxford, United Kingdom: 168-195.

[8] Koo WW, Eesley CE. 2021. "Platform Governance and the Rural-Urban Divide: Sellers' Responses to Design Change." Strategic Management Journal 42(5): 941-967.

[9] Agarwal R, Gambardella A, Olson DM. 2016. "Employee mobility and entrepreneurship a virtual special issue." Strategic Management Journal 37(13): E11-E21.

[10] Singh J, Marx M. 2013. "Geographic constraints on knowledge spillovers: Political borders vs. spatial proximity." Manage. Sci. 59(9):2056-2078.

[11] Marx M, Strumsky D, Fleming L. 2009. "Mobility, skills, and the michigan non-compete experiment." Management Science. INFORMS 55(6): 875-889.

[12] Forman C, Goldfarb A, Greenstein S. 2005. "How did location affect adoption of the commercial Internet? Global village vs. urban leadership." Journal of Urban Economics 58(3): 389-420.

[13] Huang X. 2010. "The institutional dynamics of China's great transformation." Routledge.

[14] Zhang J, Huang J, Wang J, Guo L. 2020. "Return migration and Hukou registration constraints in Chinese cities." China Econ. Rev. 63:101498.

[15] Kuang L, Liu L. 2012. "Discrimination against Ruralto-Urban Migrants: The Role of the Hukou System in China." PLoS ONE, Denson T (ed). Public Library of Science 7(11): e46932.

[16] Jiangsu Government. 2015. "Q\&A Regarding Jiangsu's Residency Permit Policy." JS.gov.cn. http://www.js.gov.cn/jsgovbz/bmwd/bmwdbs/20151 2/t20151225_415877.html.

[17] Li H, Zhang Y, Li Y, Zhou L-A, Zhang W. 2012. "Returnees Versus Locals: Who Perform Better in China's Technology Entrepreneurship?" Strategic Entrepreneurship Journal. Wiley 6(3): 257-272.

[18] Luo J, Chen J, Chen D. 2021. "Coming Back and Giving Back: Transposition, Institutional Actors, and the Paradox of Peripheral Influence." Administrative Science Quarterly. SAGE Publications Ltd 66(1): 133-176.

[19] Glaeser E, Ponzetto G. 2007. "Did the death of distance hurt Detroit and help New York?" NBER Working Paper Series.

[20] Mishkin E. 2021. "Gender and Sibling Dynamics in the Intergenerational Transmission of Entrepreneurship." Management Science. Institute for Operations Research and the Management Sciences (INFORMS) : 1-20. 
Figure 1. Mapping of REBs' performance change in all regions. Color depth and text labels indicate change in months sales (normalized; each unit roughly equals $60 \mathrm{USD}$ ).

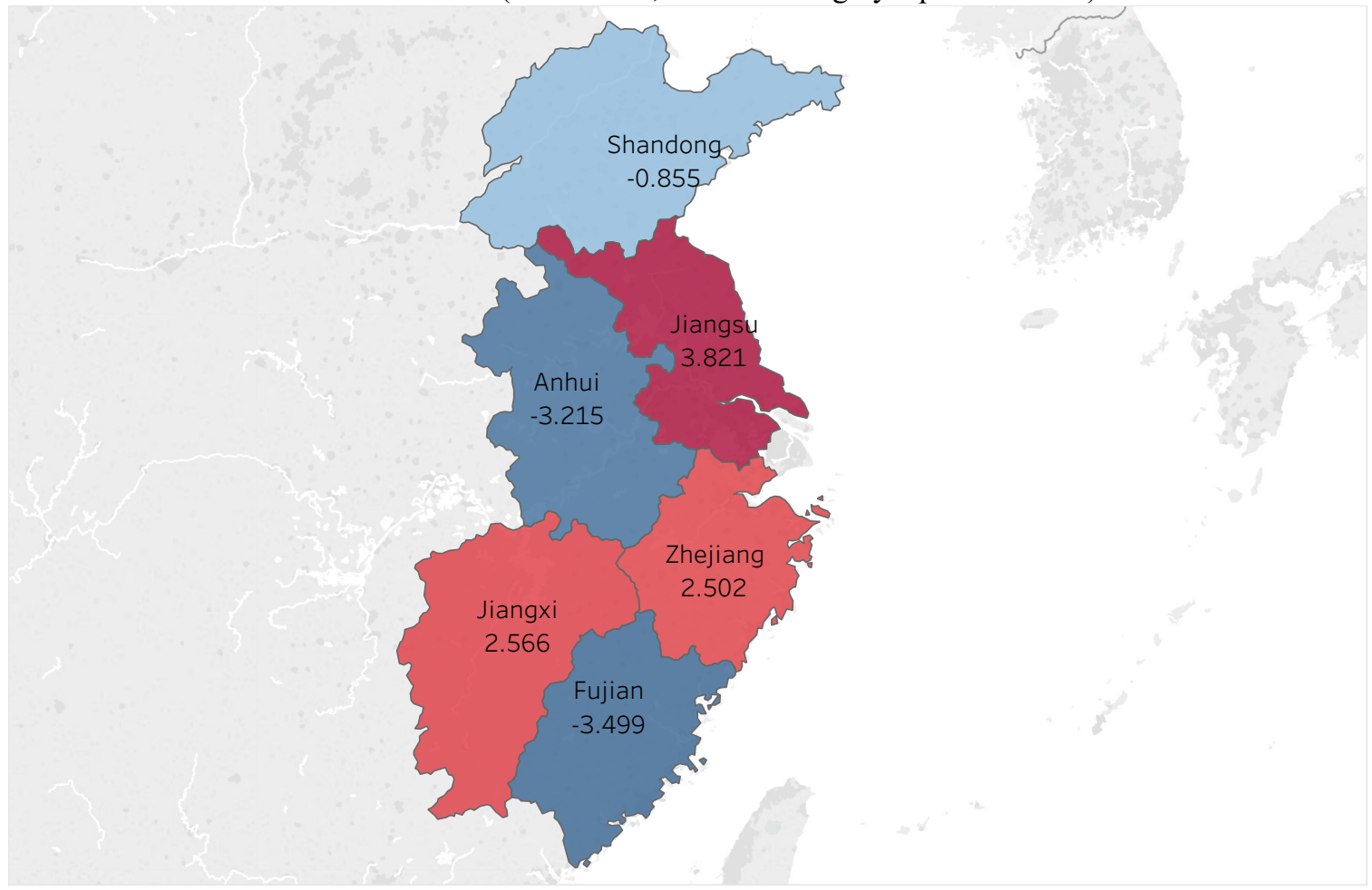

\section{Sales Change}

$-3.499 \quad 3.821$ 
Figure 2. Survival analysis of urban e-commerce businesses (UEBs) moving to rural areas. Vertical red line indicates the time of policy change.

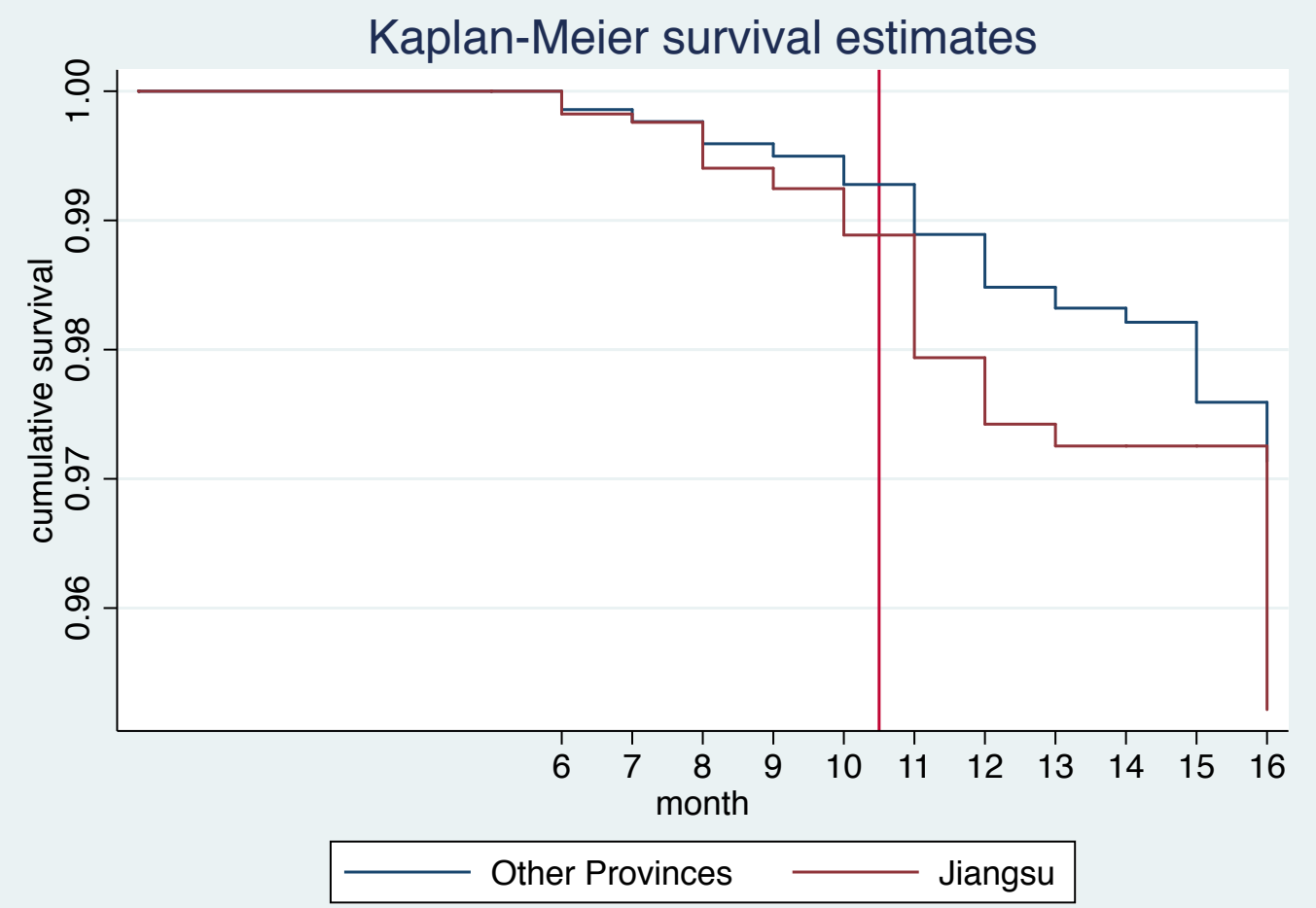


Table 1. Summary statistics and correlation matrix (14,395 business-month observations).

\begin{tabular}{|c|c|c|c|c|c|c|c|c|c|c|c|c|c|c|c|}
\hline & & Mean & Median & S.D. & Min. & Max. & 1 & 2 & 3 & 4 & 5 & 6 & 7 & 8 & 9 \\
\hline 1 & Sales & 20.59 & 0.28 & 110.45 & 0.00 & 4266.00 & 1 & & & & & & & & \\
\hline 2 & Num. Founded & 5.87 & 4.00 & 6.15 & 0.00 & 31.00 & 0.01 & 1 & & & & & & & \\
\hline 4 & Moved to Rural & 0.01 & 0.00 & 0.09 & 0.00 & 1.00 & -0.02 & 0.03 & -0.02 & 1 & & & & & \\
\hline 5 & $\log ($ Price $)$ & 1.35 & 1.22 & 0.91 & 0.00 & 7.44 & 0.13 & -0.01 & -0.12 & -0.02 & 1 & & & & \\
\hline 7 & Business Age & 16.07 & 12.00 & 13.64 & 0.00 & 51.00 & 0.16 & -0.06 & 0.14 & -0.05 & 0.07 & -0.07 & 1 & & \\
\hline 8 & Jiangsu & 0.26 & 0.00 & 0.44 & 0.00 & 1.00 & 0.04 & -0.09 & 0.05 & 0.00 & 0.06 & -0.02 & 0.03 & 1 & \\
\hline 9 & PostPC & 0.62 & 1.00 & 0.49 & 0.00 & 1.00 & 0.00 & 0.20 & -0.02 & 0.04 & 0.02 & -0.03 & -0.02 & -0.02 & 1 \\
\hline
\end{tabular}

Note: We take the logarithm of sales in the actual analysis. In this correlation table, we show the unlogged sales variable to enable easier interpretation. The sales variable is multiplied by an unknown constant. We estimate through a back-of-the-envelope calculation (by finding the average monthly sales of a Chinese e-commerce sellers in 2013, which was roughly 1200 USD, and dividing that by the average normalized sales in our sample, 20.59) that one unit of sales roughly corresponds to 60 USD. Finally, the average age of the entrepreneur is early 30 s (the dataset does not indicate the exact age of an entrepreneur, but divides it into age buckets), and $51 \%$ of the entrepreneurs are female. 